\title{
FORMAÇÃO DOCENTE: REFLEXÃO E DIDÁTICA POR UM ENSINO DE QUÍMICA ATRATIVO
}

\author{
R. C. M. ALVES ${ }^{1}$, V. R. GOMES ${ }^{2}$, A. G. NASCIMENTO ${ }^{3}$ e M. MARTINHO ${ }^{4}$ \\ Instituto Federal de Educação, Ciência e Tecnologia do Maranhão - IFMA (Campus Zé Doca) \\ regina.alves@ifma.edu.br ${ }^{1}$; verarejane@ifma.edu.br ${ }^{2}$; antoniagomes@ifma.edu.br ${ }^{3}$; \\ mailson.martinho@ifma.edu.br ${ }^{4}$
}

Artigo submetido em outubro/2012 e aceito em dezembro/2012

DOI: $10.15628 /$ rbept.2012.3462

\section{RESUMO}

O ensino de Química está no centro das preocupações de muitos pesquisadores e estudiosos da educação, pois, apesar de sua importância, tem sido considerado, por muitos alunos, como complicado, de difícil aprendizagem, enfadonho e por isso mesmo desinteressante. Muitos não conseguem tornar o ensino interessante e buscam soluções em procedimentos didáticos, acreditando que estes trarão a resposta. Tal realidade expressa uma problemática: como tornar o ensino de Química atrativo e produtor de conhecimento, utilizando os saberes didáticos? Nesse artigo tentou-se atingir essa problemática atrelada ao eixo temático que é Formação de professores para a Educação Profissional.
Esse trabalho tem como objetivo analisar a importância da reflexão e dos saberes didáticos para a formação docente tendo como foco um ensino atrativo e produtor de conhecimento. Trata-se de uma pesquisa de campo, com o uso de entrevista e observação. O caminho metodológico compreendeu momentos de leitura, reflexão e apresentação de uma Mostra Didática realizada em duas escolas públicas de Ensino Médio da cidade de Zé Doca-MA. Os resultados revelam que o exercício da reflexão aliado aos saberes didáticos oferecem uma experiência formadora indispensável à construção individual dos saberes profissionais.

PALAVRAS-CHAVE: Formação docente, Ensino, Reflexão, Saberes didáticos.

\section{TEACHER EDUCATION: TEACHING FOR REFLECTION AND A CHEMICAL TEACHING} ATTRACTIVE

\begin{abstract}
Teaching Chemistry is the main concern of many researchers and scholars in education, because, despite its importance, it has been considered by a great number of students as complicated, hard to learn, boring and, therefore, unattractive. Most teachers can't manage to make it interesting, so they seek a solution in didactic procedures, believing to be the answer. This reality exposes a problematic: how to turn Chemistry into a more attractive and learning generator topic, using didactic knowledge? This article tries to reach this problem linking it to the thematic area of Teachers
\end{abstract}

Training for Professional Education. This work aims to analyze the importance of reflection and didactic knowledge to teachers training focusing on attractive teaching and learning generator. It's a field research, using interviews and observations. The methodological way included moments of reading, reflection and presentation of a Didactic Show held by two public high schools from Zé Doca (MA). The results reveal that constant reflection related to didactic knowledge offer a forming experience necessary to individual development of professional knowledge.

KEYWORDS: teaching, teachers training, reflection, didactic knowledge. 


\section{INTRODUÇÃO}

O ensino de Química está no centro das preocupações de muitos pesquisadores e estudiosos da educação no país, pois, apesar de sua importância, tem sido considerado, por vários alunos, como complicado, de difícil aprendizagem, enfadonho, sem sentido e desinteressante. Muitos professores não sabem como agir pedagogicamente para tornar o ensino atrativo, buscam soluções em simples procedimentos didáticos, acreditando que estes trarão a resposta e, esquecem que a prática exige um exercício de reflexão contínuo para que os saberes necessários à docência sejam construídos.

Diante das exigências da sociedade ocorrem mudanças no mundo do trabalho, na família, na escola, no ser humano. Não basta apenas adquirir saberes determinados pelas instituições de formação, é preciso adquirir autonomia para novas construções que atendam às necessidades de aprendizagem de quem ensina e de quem é ensinado. Nesse sentido, há muito trabalho a ser feito pelas instituições formadoras, onde um dos passos é oportunizar e instrumentalizar o aluno tornando-o capaz de refletir criticamente sobre os componentes teóricos e práticos que envolvem o ensino.

Nesse contexto compromissos precisam ser assumidos e um deles é repensar a Didática do ensino e para o ensino, uma vez que este último é o objeto sobre a qual a Didática lança seus estudos e fundamentos teóricos.

A preocupação com o ensino de Química faz emergir também a preocupação com a formação dos licenciandos em Química do Instituto Federal de Educação, Ciência e Tecnologia do Maranhão, pois compreende-se que é necessário oferecer a estes experiências ricas em aprendizagem e que os conhecimentos da Didática possam ser utilizados em situações reais, com desafios que estimulem e provoquem reflexões sobre o fazer docente, de maneira que o ensino seja atrativo e se constitua espaço de construção do conhecimento.

Esse contexto motivou o desenvolvimento de uma pesquisa de campo, tendo como interlocutores, no primeiro momento, vinte e nove alunos de licenciatura em Química; e no segundo momento, cento e vinte e oito alunos do ensino médio. As atividades foram de estudos e discussão na sala de aula, com base em diferentes autores, dentre os quais: Mizukami (2013), Alarcão (2011), Freire (2011) e Candau (2010), seguido de atividade prática para a qual se escolheu realizar uma Mostra Didática intitulada Química Alternativa, realizada em duas escolas públicas da cidade de Zé Doca-MA.

Os resultados da pesquisa demonstraram que a Didática Fundamental aliada ao exercício da reflexão contribuem para o desenvolvimento de um ensino de Química dinâmico e produtor de conhecimento. A relevância do trabalho está em contribuir com a formação profissional dos futuros professores de Química, e em desmistificar a ideia que o ensino de Química é de difícil compreensão.

\section{REVISÃO BIBLIOGRÁFICA}

\subsection{Reflexão: uma ação necessária}

Diante da sociedade do conhecimento, que integra uma diversidade de saberes, com um 
alcance científico e tecnológico ora presenciados, desencadeando mudanças políticas, econômicas e culturais, que incidem sobre a educação, cabe às Instituições formadoras, através de seus sujeitos, um repensar, um refletir conjunto, sobre a prática docente dos futuros profissionais da educação. Essa reflexão deve ser uma constante tanto para o professor quanto para o aluno. 0 exercício do pensar é necessário em diversos âmbitos e áreas da atuação docente, sendo essencial para que o aluno de licenciatura compreenda a relação teoria e prática e perceba uma continuidade entre o que o curso de formação lhe oferece e a prática a ser vivenciada no interior da escola.

Obviamente é necessária uma construção coletiva para que a teoria não perca seu fundamento e ganhe vida; e que a prática docente não esvazie diante do seu caráter formador, o que torna mais legítimo o valor do exercício da reflexão. Nesse ponto, alinha-se o pensamento com a afirmação de Paulo Freire (2011, p. 24) de que "a reflexão crítica sobre a prática se torna uma exigência da relação Teoria/Prática sem a qual a teoria pode ir virando blá-blá-blá e a prática, ativismo".

É pertinente lembrar que embora a capacidade reflexiva seja algo próprio do ser humano é preciso criar, estimular, situações favoráveis ao seu desenvolvimento. A despeito das dificuldades para desenvolvê-la Alarcão destaca:

É repetidamente afirmado, nos estudos em que o fator da reflexão é tido em consideração, a dificuldade que os participantes revelam em pôr em ação os mecanismos reflexivos, sejam eles crianças, adolescentes ou adultos [...]. É preciso fazer um esforço grande para passar do nível meramente descritivo ou narrativo para o nível em que se buscam interpretações articuladas e justificadas e sistematizações cognitivas.

Para Isabel Alarcão (2011), um processo formativo que trabalhe na perspectiva dos níveis mais elaborados de interpretação e sistematização necessita de diálogo, um instrumento valioso, a ser considerado na relação para conosco, para como os outros e com a realidade. Isso traz uma exigência: "os formadores de professores têm uma grande responsabilidade na ajuda ao desenvolvimento desta capacidade de pensar autônoma e sistematicamente".

Ajudar o aluno a pensar sistematicamente, autonomamente sobre a prática docente se tornou uma inquietação ao trabalhar a disciplina Didática no curso de Licenciatura em Química. Sendo a Química uma disciplina encarada como de difícil aprendizagem e a Didática como aquela que mostrará o caminho metodológico mais acertado para que o ensino aconteça, como contribuir para que o ensino de Química seja atrativo e esclarecedor? Esse trabalho requer o transpor da Didática Instrumental, conceituada por Candau (2010, p. 13) como "um conjunto de conhecimentos técnicos sobre o "como fazer" pedagógico, conhecimentos estes apresentados de forma universal e, consequentemente desvinculados dos problemas relativos ao sentido e aos fins da educação".

Ir além desse conhecimento técnico nos coloca no espaço da Didática Fundamental, que para Candau (2010, p. 15) tem um caráter multidimensional integrando as dimensões técnica, humana e política. A dimensão técnica não se separa da política, e segundo a autora, deve ser discutida e orientada por um projeto político-social, o que requer um trabalho vivido no contexto da problemática educacional. Assim, para a análise de uma prática concreta, após estudos e discussões na sala de aula, os alunos organizaram uma Mostra Didática, visto que a mesma se 
configurou como uma oportunidade do real planejamento e explicitação de diferentes conteúdos de maneira dinâmica, numa relação direta com os alunos do Ensino Médio.

A Didática Fundamental, também busca, segundo Candau (2010), analisar os pressupostos que fundamentam a abordagem metodológica do ensino, assim foi realizado um estudo detalhado das abordagens do ensino levando a várias reflexões; o que permitiu também a escolha de materiais alternativos para serem utilizados na Mostra Didática.

\section{METODOLOGIA}

O caminho metodológico percorrido neste trabalho compreende um estudo bibliográfico e uma pesquisa qualitativa de campo realizada com alunos do sétimo período de Licenciatura em Química do Instituto Federal de Educação Ciência e Tecnologia do Maranhão, Campus Zé Doca (MA).

Para tal metodologia a coleta de dados se fez com a realização de entrevista, que segundo Richardson (2011, p. 207) "é uma técnica importante que permite o desenvolvimento de uma estreita relação entre as pessoas. É um modo de comunicação no qual determinada informação é transmitida de uma pessoa A para uma pessoa B".

$\mathrm{Na}$ concretude do trabalho as atividades foram organizadas e vivenciadas em seis momentos, a saber:

1- Leitura de material bibliográfico em torno da temática em questão; discussão em sala de aula junto aos alunos interlocutores da pesquisa, com relação a importância da reflexão para a prática docente, como diz Freire (2011) e Alarcão (2011); resenha do livro referente as abordagens do ensino de Mizukami (2013); estudo e reflexão sobre a Didática Instrumental e Fundamental com Candau (2010);

2- Preparação de uma Mostra Didática com materiais alternativos. O grupo de licenciandos foi dividido em seis equipes, cada equipe trabalhou três conteúdos com demonstração experimental e auxílio de material alternativo, como por exemplo: grupo 1- Trabalhou indicadores de ácido/base, Reação química e Cristalização;

3- Realização da Mostra em duas escolas do Ensino Médio: o Centro de Ensino Princesa Isabel na modalidade da Educação de Jovens e Adultos (EJA) e o Centro de Ensino Nelson Serejo de Carvalho (CEMA) onde funciona o nível Médio;

4- Entrevista realizada com os alunos das escolas mencionadas;

5- Avaliação da Mostra com os licenciandos;

6- Análise dos dados coletados e produção de relatório.

Para a produção de dados, foi utilizada a técnica de observação, que segundo Richardson (1999), é de grande proveito nesse tipo de pesquisa devido a capacidade com que adentra a complexidade de um problema. O que permitiu observar o desempenho dos licenciandos diante dos estudos feitos e da realização e desafios da Mostra Didática.

$\mathrm{Na}$ Mostra Didática foram apresentados na Prática 1 assuntos como Termodinâmica(equilíbrio térmico) com o objetivo de demonstrar a ocorrência do equilíbrio térmico em substâncias com temperaturas diferentes; na Prática 2 foi apresentado as Propriedades da matéria(densidade) com o objetivo de compreender que cada substância tem 
uma densidade definida e explicar como o sal interfere na densidade da água; e na Prática 3 foi abordado o assunto Termodinâmica(capacidade calorífica) com o objetivo de visualizar como a água absorve calor devido suas propriedades e observar a capacidade calorífica da água, em que que foi utilizado experimentos pelos alunos com procedimentos metodológicos e resultados/discussões sob a orientação de um(a) professor(a).

De acordo com as Práticas na Mostra Didática, pôde-se perceber o enriquecimento de saberes tanto pelos docentes como discentes, nesse sentido foi demonstrado na prática os experimentos referentes a conteúdos trabalhados na sala de aula, o que fez que gerar mais saberes para uma reflexão e um ensino de Química mais atraente.

\section{RESULTADOS E DISCUSSÕES}

Os resultados alcançados revelam a importância dos momentos de estudo, reflexão e análise bem como da realização da Mostra Didática para a formação inicial dos licenciandos em Química.

No primeiro momento do caminho metodológico, observou-se um crescente desenvolvimento no nível de interpretação e reflexão dos formandos. Antes dos estudos, apontavam falhas no ensino da Química, mas não conseguiam estruturar uma análise considerando as abordagens do ensino, não sabiam, por exemplo, que elementos caracterizam e diferenciam a abordagem tradicional de uma abordagem comportamental ou sociocultural e que as concepções, por exemplo de homem, conhecimento, educação, escola, ensino-aprendizagem, metodologia e avaliação influenciam toda a prática docente incidindo diretamente sobre o ensino.

Ao longo dos estudos, os formandos também expressavam preocupação e questionavam como harmonizar os conhecimentos já adquiridos para que o ensino de Química fosse proveitoso, esse foi um momento importante para a formação do futuro professor, pois oportunizar momentos para questionamentos é de grande valia. Alarcão (2011, p.62), corrobora com esse pensamento ao afirmar que "a capacidade de questionarmos e de nos questionarmos a nós próprios é um motor de desenvolvimento e aprendizagem".

Pedindo para que cada grupo avaliasse a Mostra Didática surgiram respostas elucidativas do potencial da atividade realizada, das quais destacam-se os seguintes trechos:

- "A mostra contribuiu muito para a interação entre nós e os alunos da Educação de Jovens e Adultos (EJA) e do Ensino Médio; nos deu um novo horizonte de conquistas e desafios que o profissional da educação vai enfrentar no decorrer do processo educacional".

- "Durante a mostra pudemos trocar ideias, obter experiências novas, nos deparar com a atmosfera do princípio da dúvida, aprender e ensinar numa troca de papéis de uma forma que superou a todos". Ressalta-se a importância de repetir momentos de valores, como esse, para o crescimento, desenvolvimento e a descoberta da bela profissão que apresenta-se como professor".

Os relatos demonstram que uma das riquezas da Mostra foi a experiência real que os licenciandos obtiveram, o que os fez inclusive ver a beleza da profissão docente, não foi dito aos discentes o que deveriam fazer, mas ofereceu-lhes a oportunidade de fazerem, de interagirem com os alunos, de serem questionados, de sentirem os desafios do ofício docente. A experiência 
da Mostra teve um caráter formador no momento que caracterizou bem o ato de ensinar, pois como afirma Paulo Freire (2011, p.24), "ensinar não é transferir conhecimento, mas criar as possibilidades para a sua produção ou a sua construção".

Analisando a avaliação feita pelos formandos vale destacar os trechos a seguir:

- "A mostra foi bastante proveitosa, pois conseguimos alcançar os objetivos esperados quanto ao conhecimento que foi repassado para os alunos. (...) Houve a participação dos alunos do Ensino Médio, colaboração e interação ao serem apresentados os experimentos. Os alunos tiraram suas dúvidas".

- "Todo o processo serviu para ver na prática o que só se via na teoria".

- "Esse trabalho realizado na escola permitiu fazer uma problematização a partir da prática social dos alunos".

- “(...) Os desafios permitiram a construção de novas estratégias. As perguntas dos alunos nos fizeram refletir e buscar novos elementos para a abordagem dos temas".

Tais avaliações permitiram dizer que os formandos de Química desenvolveram habilidades e conhecimentos, pois foram capazes de construir novas estratégias de abordagem, problematizaram os temas partindo dos conhecimentos que os alunos do ensino médio já possuíam, e colocaram em prática o saber-fazer diante dos desafios que enfrentaram, e tais desafios só são percebidos em situações concretas, respondendo assim a partir das exigências de uma formação docente, pois como destaca Pimenta (2007, p. 18):

(...) espera-se da licenciatura que desenvolva nos alunos conhecimentos e habilidades, atitudes e valores que thes possibilitem permanentemente irem construindo seus saberes-fazeres docentes a partir das necessidades e desafios que o ensino como prática social lhes coloca no cotidiano.

As situações desafiadoras que permitem interações com os discentes fortalecem a aquisição de saberes pedagógicos e didáticos. Esse saberes segundo Pimenta (2007), alcançaram diferentes destaques ao longo dos anos, por vezes enfocando a relação professor-aluno, outras vezes, a motivação, as técnicas de ensinar, ora predominavam os saberes científicos, ora os das experiências. No momento atual como pensar os saberes docentes? A autora comungando da ideia de outros teóricos afirma que deve-se construir os saberes pedagógicos com base nas necessidades do campo pedagógico, seria uma reinvenção de saberes que começa com a prática social do ensinar e provoca a reconsideração dos saberes da docência na própria formação profissional.

O exercício do ensinar se desenvolve num contexto de múltiplas interações que apontam condicionantes diversos e surgem em situações concretas que exigem habilidade do profissional para enfrentar situações das mais diversas. Dessa maneira, ao permitir um contato direto com os educandos do Ensino Médio, os conhecimentos didáticos concretizados na Mostra integram um processo formador.

Ao final da Mostra, os licenciandos de Química ao terem a compreensão a partir de estudos anteriores e a importância do ato de avaliar o trabalho oferecido aos alunos, realizaram uma entrevista com sessenta alunos do Centro de Ensino Princesa Isabel que oferta Ensino Médio na 
Modalidade EJA; e sessenta e oito alunos do Centro de Ensino Nelson Serejo de Carvalho (CEMA) que oferta o Ensino Médio Regular, mesclando séries diferentes.

A Figura 1 refere-se ao uso de material alternativo envolvendo os conteúdos ministrados pelo professor em sala de aula, em que os alunos foram questionados se no decorrer das aulas, alguma vez houve a utilização de recursos alternativos como auxílio para a aprendizagem.

No Centro de Ensino Princesa Isabel, 12 alunos responderam sim e 48 responderam não; no Centro de Ensino Nelson Serejo de Carvalho (CEMA), 38 discentes responderam sim e 30 responderam não. Os valores percentuais dos alunos estão expressos na Figura 1.

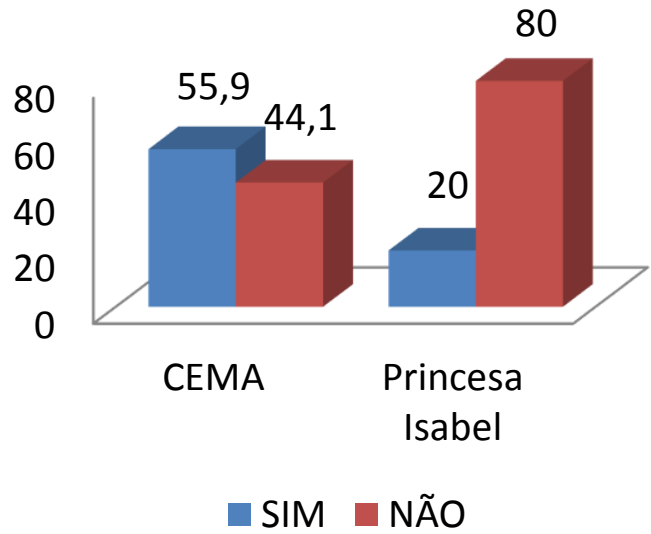

a)

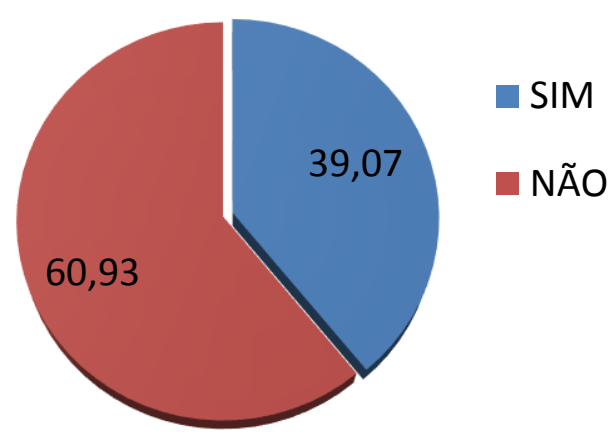

b)

Figura 1: Percentual de alunos que assistiu aula com auxílio de material alternativo nas escolas CEMA e Princesa Isabel (\%) -a) por escola; b) global b).

Dentre os 128 alunos pesquisados, no Centro de Ensino Nelson Serejo de Carvalho (CEMA), $55,9 \%$ responderam sim quanto à utilização de material alternativo na sala de aula e $44,1 \%$ responderam não. Com relação a resposta não, observa-se ainda uma preocupação da não utilização do material alternativo no trabalho do profissional na escola, pois sabe-se que utilizando materiais alternativos de forma concreta a aprendizagem torna-se mais significativa, com sentido.

No Centro de Ensino Princesa Isabel, 20\% dos alunos responderam sim e $80 \%$ responderam não. Dessa forma, percebe-se que é necessário um maior engajamento e planejamento coletivo por parte da gestão e dos docentes referente à utilização de materiais alternativos nas aulas nas referidas Escolas.

Nas duas escolas acima citadas, percebeu-se um número expressivo de alunos que não tiveram a oportunidade de aprender química com o uso de materiais alternativos, os mesmos relataram que nas aulas utilizava-se muito o quadro e o livro didático, resultando em aulas tradicionais expositivas. Sendo assim, para que isso não ocorra, é necessário colaborar, sugerindo transformações, partindo dos professores e dos grupos gestores das instituições através da formação de professores.

De acordo com a Figura 2, observa-se que $100 \%$ dos alunos entrevistados responderam que com a utilização de materiais alternativos a aprendizagem dos conteúdos torna-se mais atrativa e com significado. 


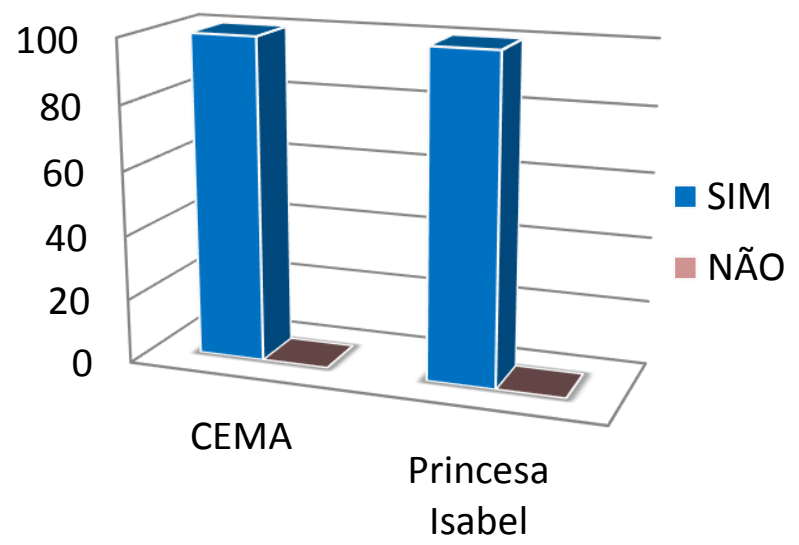

Figura 2: Maior facilidade de aprendizagem com a utilização de materiais alternativos e/ou realização de experiências (\%).

Percebe-se então, que o ensino de Química torna-se mais prazeroso quando há uma vinculação entre o mundo do aluno-cidadão e o mundo da Química, através de atividades que o levem a refletir, compreender, discutir e agir sobre seu mundo, fazendo-se assim "Educação através da Química".

A utilização do material alternativo no ensino supracitado apresenta-se como um meio de educação para a vida, relacionando os conteúdos aprendidos com o cotidiano dos alunos e com outras áreas do conhecimento, formando a totalidade que explica e interpreta a presença do homem na Terra e o sentido do desenvolvimento científico.

A Figura 3 refere-se a avaliação da mostra didática aplicada nas duas escolas. Observa-se então que, no Centro de Ensino Princesa Isabel, 48,3\%responderam que a Mostra foi ótima; 50\% afirmaram que foi boa; e 1,7\% afirmaram ser regular; no Centro de Ensino Nelson Serejo de Carvalho (CEMA), 69,1\% responderam que a Mostra Didática foi ótima; e 30,9\% responderam que a Mostra foi boa.

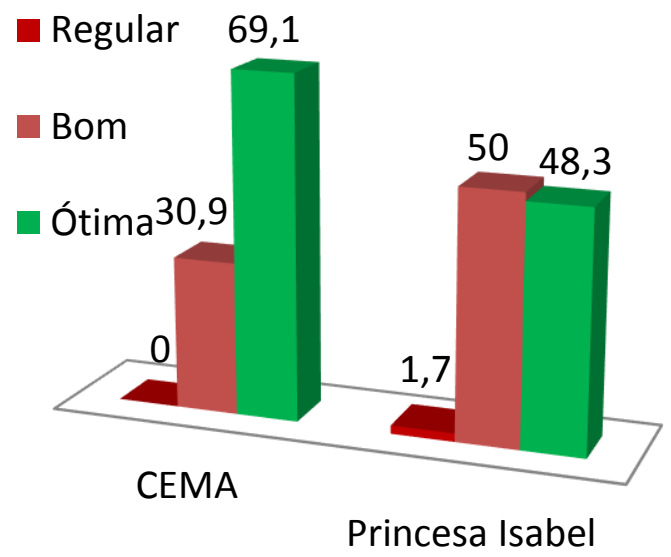

Figura 3: Avaliação sobre a Mostra Didática nas escolas CEMA e Princesa Isabel (\%)

De acordo com Oliveira (2010), a busca de nova perspectiva é necessária e entende-se que a melhoria da qualidade do ensino de Química passa pela definição de uma metodologia de ensino que privilegie a contextualização como uma das formas de aquisição de dados da realidade, oportunizando ao aprendiz uma reflexão crítica do mundo e um desenvolvimento cognitivo, através de seu envolvimento de forma ativa, criadora e construtiva com os conteúdos abordados 
em sala de aula. Nesse sentido, a formação contínua de professores ajudará na busca de novos horizontes para o Ensino da Química no Ensino Médio.

\section{CONCLUSÃO}

Compreende-se que no espaço rico da prática que é a sala de aula, onde os saberes experienciais se formam, reside uma grande oportunidade para que a informática, pela exploração de recursos e situações de aprendizagens por ela permitidas, se torne uma auxiliar na construção dos saberes experienciais. O caminhar junto com a Didática Fundamental se traduz em uma oportunidade de reflexão partindo de estudos e experiências reais.

A utilização do material alternativo e/ou realização de experiências na execução da Mostra Didática aplicada nas duas escolas públicas estaduais supracitadas permite apontar algumas soluções. O trabalho centrado no professor e no aluno não se caracteriza por apresentar um material didático pronto e acabado. Caracteriza-se, sim, por exigir a contribuição do professor e do aluno, para que o conhecimento não seja simplesmente assimilado, mas constantemente produzido, construído pelo próprio aluno, em conjunto com seu professor.

A prática da interação entre alunos e professores é uma forma de buscar soluções para sanar os conflitos gerados no cotidiano da sala de aula, com a utilização de materiais alternativos e/ou experiências, dessa maneira, é possível maior êxito na aprendizagem do conteúdo ensinado; logo, é pertinente a reflexão na formação do docente para que aconteça um ensino de Química atrativo.

Então, a mensagem importante deste artigo é alertar o professor de Química para alternar o seu estilo de ensinar, com o objetivo principal de facilitar a aprendizagem, se isto acontecer estará contribuindo significativamente para a melhoria do ensino e com certeza os alunos se motivarão a estudar química e terão outra visão desta ciência, que não é só de decorar "FÓRMULAS, PROPRIEDADES E EQUAÇÕES QUÍMICAS", mas também de aplicar na prática materiais alternativos que venham a subsidiar o trabalho do docente e a aprendizagem dos discentes exigindo assim, uma reflexão dos saberes e, tornando o ensino de Química mais interessante e atraente.

\section{REFERÊNCIAS}

1. ALARCÃO, Isabel. Professores reflexivos em uma escola reflexiva.8.ed. São Paulo: Cortez, 2011.

2. CANDAU, Vera Maria (Org.). Rumo a uma nova didática. 20. ed. Rio de Janeiro: Vozes, 2010.

3. FREIRE, Paulo. Pedagogia da autonomia: saberes necessários à prática educativa. 33. ed. São Paulo: Paz e Terra, 2011.

4. LIMA, Maria da Glória Soares Barbosa. Sujeitos e saberes, movimento de auto-reforma da escola: In: MENDES SOBRINHO, José Augusto de Carvalho: CARVALHO, Marlene Araújo de (Orgs). Formação de professores e práticas docentes: Olhares contemporâneos. Belo Horizonte: Autêntica, 2010. 
5. OLIVEIRA, Henrique Rolim Soares. A Abordagem da Interdisciplinaridade, Contextualização e Experimentação nos livros didáticos de Química do Ensino Médio. Monografia (Curso de Licenciatura em Química). Universidade Estadual do Ceará. Fortaleza - CE, 2010.

6. PIMENTA, Selma Garrido (Org.). Saberes Pedagógicos e atividade docente.5.ed. São Paulo: Cortez, 2007.

7. PINTO, Álvaro Vieira. Sete lições sobre educação de adultos. 16. Ed. São Paulo: Cortez, 2010.

8. RICHARDSON, R. J. Pesquisa social: métodos e técnicas. 3.ed. São Paulo: Atlas, 1999. 